\title{
Nanosized strontium aluminate phosphors prepared via a reverse microemulsion route
}

\author{
Chung-Hsin Lu*, Shih-Yen Chen, Chia-Hao Hsu \\ Department of Chemical Engineering, National Taiwan University, Taipei, Taiwan, ROC
}

\begin{abstract}
Nanosized strontium aluminate phosphors co-activated by $\mathrm{Eu}^{2+}$ and $\mathrm{Dy}^{3+}$ were prepared via a novel reverse microemulsion process. This new synthesis technique lowered the synthesis temperature of $\mathrm{SrAl}_{2} \mathrm{O}_{4}: \mathrm{Eu}^{2+}, \mathrm{Dy}^{3+}$ phosphors to as low as $900{ }^{\circ} \mathrm{C}$, and also reduced the particle size to the nanometer scale (around $40 \mathrm{~nm}$ ). In the microemulsion process, the constituent cations were trapped by numerous nano-scaled micelles, leading to a shortening of the inter-diffusion length and enhancement of the precursor reactivity. The excitation intensity and emission peaks of nanosized $\mathrm{SrAl}_{2} \mathrm{O}_{4}: \mathrm{Eu}^{2+}$, Dy ${ }^{3+}$ phosphors significantly increased with increasing heating temperatures.
\end{abstract}

(C) 2007 Elsevier B.V. All rights reserved.

Keywords: Microemulsion; Strontium aluminate; Phosphors

\section{Introduction}

Aluminate phosphors have been extensively investigated because of their high chemical stability and bright emission characteristics in the visible light region [1-3]. Among these phosphors, strontium aluminate phosphors doped with rareearth metal ions have emerged as materials with great potential. Europium-ion activated alkaline earth aluminates $\left(\mathrm{MAl}_{2} \mathrm{O}_{4}\right.$ : $\mathrm{Eu}^{2+}, \mathrm{M}=\mathrm{Ca}, \mathrm{Sr}, \mathrm{Ba}$ ) are known to exhibit good phosphorescent emission due to their high quantum efficiency in the visible light region [4]. In general, the synthesis of these phosphors requires high heating temperatures (i.e. $1400-1600^{\circ} \mathrm{C}$ ) owing to the insufficient diffusion and low reactivity of the starting materials $[5,6]$.

Various approaches, such as sol-gel and combustion techniques, have been used to control the morphology and particle size of strontium aluminate phosphors $[7,8]$. These methods can produce small particles at low temperatures; however, the phase purity remains a problem. The reverse microemulsion process is one of the most useful techniques for synthesizing complex inorganic compounds at ultra fine particle sizes with controlled morphology. The micelles that trap the reactive species can restrict the particle growth. This technology has been demon-

\footnotetext{
* Corresponding author.

E-mail address: chlu@ntu.edu.tw (C.-H. Lu).
}

strated to improve the characteristics of various kinds of ceramic materials [9-11].

The aim of this study is to lower the synthesis temperature for preparing pure strontium aluminate phosphors with bright luminescence via the reverse microemulsion process. The effects of thermal treatments on the properties of strontium aluminate phosphors were investigated. The relation between the photoluminescent characteristics of emulsion derived powders and the preparation conditions were also studied.

\section{Experimental}

Europium and dysprosium ions doped strontium aluminate were prepared via the reverse microemulsion route. Strontium nitrate, aluminum nitrate, europium oxide, and dysprosium oxide were dissolved in de-ionized water to form an aqueous solution. Polyoxyethylene(10) octylphenyl ether (OP-10) and $n$-hexyl alcohol were used as the surfactant and co-surfactant added to cyclohexane to prepare the oil phase. The aqueous solution was dripped into the oil phase forming a microemulsion system. The formed microemulsion was added drop by drop into hot kerosene with a micro-pump at around $180^{\circ} \mathrm{C}$ for water evaporation. The microemulsion solution was further heated to $500^{\circ} \mathrm{C}$ for $2 \mathrm{~h}$ in air to remove the residual oil to obtain the precursor powders. The obtained white powders were ground and calcined at different temperatures in a reducing atmosphere (vol. $5 \%$ of $\mathrm{H}_{2}$ gas and vol. $95 \%$ of $\mathrm{N}_{2}$ gas) for $3 \mathrm{~h}$. 
$\mathrm{X}$-ray diffraction (XRD) analysis was performed to investigate the crystal structures of the calcined specimens derived from the reverse microemulsion process by employing a MAC M03 XHF diffractometer using Ni filtered $\mathrm{Cu} \mathrm{K} \alpha$ radiation as the $\mathrm{X}$-ray source at $40 \mathrm{kV}, 30 \mathrm{~mA}$. The morphology and average particle size of the obtained powders were examined using a transmission electron microscope (TEM, Hitachi H-7100). The photoluminescence characteristics and decay time of the phosphors were analyzed utilizing a fluorescence spectrophotometer (PL, Hitachi F-4500) which uses a Xe lamp as an excitation source at room temperature.

\section{Results and discussion}

To prepare emulsions with good stability in the adopted system, a ternary phase diagram consisting of oil, water and surfactant/co-surfactant at room temperature (about $25^{\circ} \mathrm{C}$ ) was established in a pilot experiment as shown in Fig. 1. The shaded area represents the transparent reverse microemulsion region. In this region, the immiscible oil and aqueous phases are stabilized by the coexistence of the surfactant and co-surfactant, and a thermodynamically stable microemulsion is produced in the form of well-dispersed nano-reactors [12]. Based on the ternary phase diagram, a specific composition for forming a stable microemulsion was chosen. The surfactant and co-surfactant were added into cyclohexane at a volume ratio of 3:2:10, respectively, to form the oil phase. The aqueous and oil phase solutions were mixed at a water-to-oil volume ratio of 1:9 to form a transparent microemulsion solution.

The crystal structures of the phosphors calcined at various temperatures were investigated by XRD. The results are shown in Fig. 2. With $750{ }^{\circ} \mathrm{C}$ heating for $3 \mathrm{~h}$, only an amorphous phase was formed. As the temperature reached $800^{\circ} \mathrm{C}$, the diffraction peaks belonging to $\mathrm{SrAl}_{2} \mathrm{O}_{4}$ phase were observed without the coexistence of any other intermediate phases. It was demonstrated that the microemulsion derived precursors were directly transformed into the crystalline $\mathrm{SrAl}_{2} \mathrm{O}_{4}$ phase during the calcination process. When the calcination temperature was raised to $900^{\circ} \mathrm{C}$, the obtained diffraction pattern was consistent with

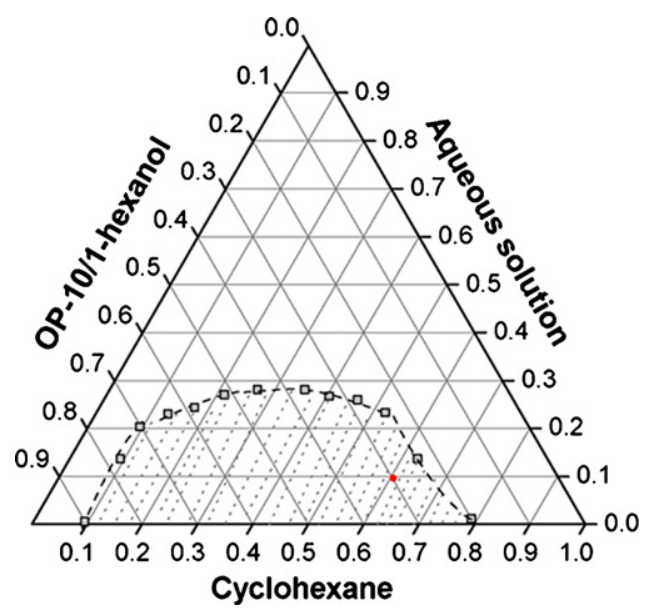

Fig. 1. Ternary phase diagram composed of the aqueous solution, cyclohexane and mixed 1-hexanol/OP-10.

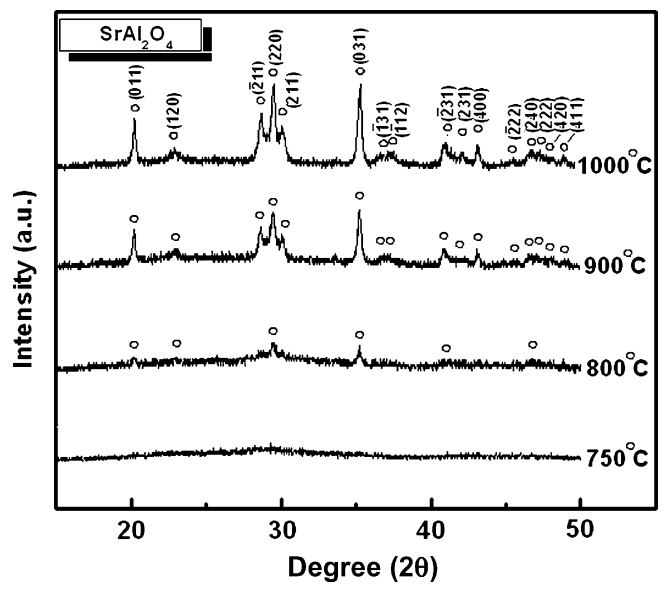

Fig. 2. X-ray diffraction patterns of the reverse microemulsion derived $\mathrm{SrAl}_{2} \mathrm{O}_{4}$ : $\mathrm{Eu}^{2+}, \mathrm{Dy}^{3+}$ phosphors heated at various temperatures in reducing atmosphere for $3 \mathrm{~h}$.

the data reported in ICDD [13], indicating that a pure $\mathrm{SrAl}_{2} \mathrm{O}_{4}$ phase was successfully prepared at a temperature as low as $900{ }^{\circ} \mathrm{C}$. When the heating temperature was further increased to $1000^{\circ} \mathrm{C}$, the crystallinity of the powders was further enhanced. In the conventional solid-state process, the required temperature for synthesizing $\mathrm{SrAl}_{2} \mathrm{O}_{4}$ is around $1400-1600{ }^{\circ} \mathrm{C}[5,6]$. It is clearly indicated that the microemulsion process can significantly lower the heating temperature for preparing $\mathrm{SrAl}_{2} \mathrm{O}_{4}$ phase. In the microemulsion system, the constituent cations are trapped by numerous nano-scaled micelles, leading to a shortened intermolecular diffusion distance between reactants and enhanced precursor activity. As a result, the heating temperature for synthesizing pure phased $\mathrm{SrAl}_{2} \mathrm{O}_{4}$ can be efficiently lowered.

The microstructure of the 900 and $1000^{\circ} \mathrm{C}$-calcined $\mathrm{SrAl}_{2} \mathrm{O}_{4}: \mathrm{Eu}^{2+}, \mathrm{Dy}^{3+}$ phosphors derived via the reverse microemulsion method is shown in Fig. 3. The particle size of the $900^{\circ} \mathrm{C}$-heated powders was around $40 \mathrm{~nm}$. With an increase in the calcination temperature, the particles of the prepared powders enlarged. The particle size of the $1000^{\circ} \mathrm{C}$-heated powders was around $50 \mathrm{~nm}$. The particle size of $\mathrm{SrAl}_{2} \mathrm{O}_{4}: \mathrm{Eu}^{2+}, \mathrm{Dy}^{3+}$ phosphors prepared via the solid-state method is about several micrometers [5], much larger than that of the microemulsion derived powders. The small particle size of the microemulsion derived powders is attributed to the confinement of the constituent cations by nano-scaled micelles and thereby restriction in the particle growth. This cage effect by the micelles results in the formation of nano-particles [14].

The excitation spectra monitored for 524-nm emission in the prepared $\mathrm{SrAl}_{2} \mathrm{O}_{4}: \mathrm{Eu}^{2+}, \mathrm{Dy}^{3+}$ phosphors are illustrated in Fig. 4. A broad band with a maximum at around $360 \mathrm{~nm}$ was observed. This broad band corresponded to $\mathrm{Eu}^{2+}$ electron transition lying in the band gap region of the host matrix. The excitation intensity of the phosphor calcined at $800^{\circ} \mathrm{C}$ was low because of incomplete formation of the $\mathrm{SrAl}_{2} \mathrm{O}_{4}$ phase and its low crystallinity. As the synthesis temperature increased, the amount of $\mathrm{SrAl}_{2} \mathrm{O}_{4}$ phase was increased and the crystallinity was enhanced, the intensity of the excitation peak was greatly increased. The peak position of the excitation peaks of prepared 

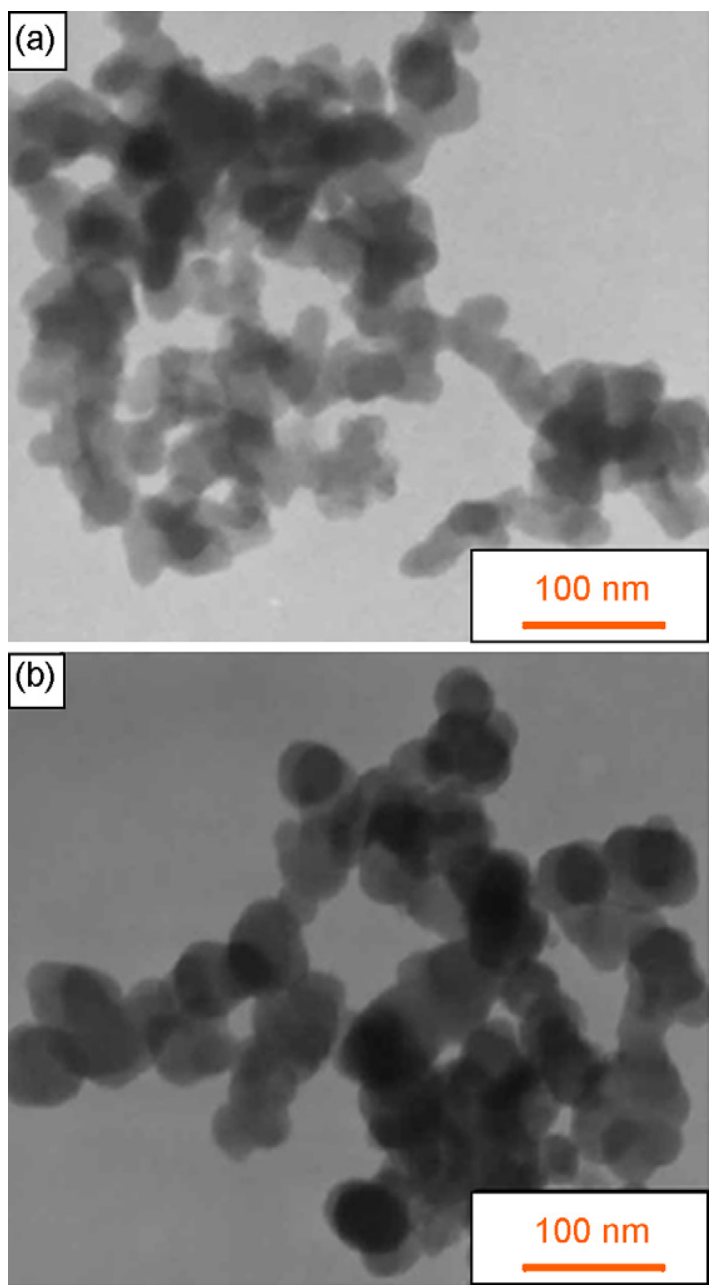

Fig. 3. TEM images of the (a) $900^{\circ} \mathrm{C}$ and (b) $1000^{\circ} \mathrm{C}$-heated $\mathrm{SrAl}_{2} \mathrm{O}_{4}: \mathrm{Eu}^{2+}$, $\mathrm{Dy}^{3+}$ phosphor prepared via the reverse microemulsion process.

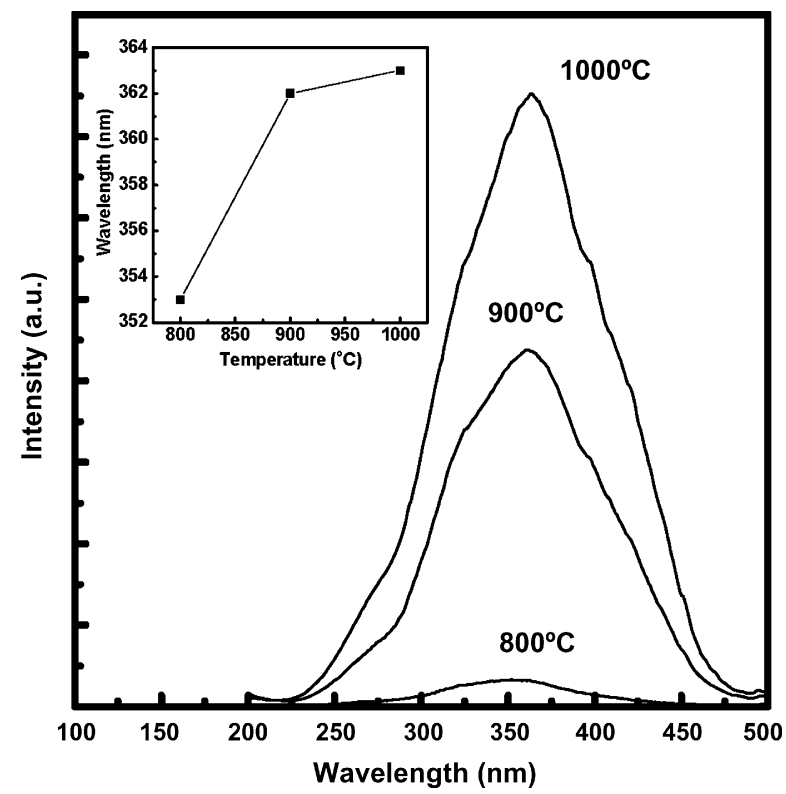

Fig. 4. Excitation spectra of the reverse microemulsion derived $\mathrm{SrAl}_{2} \mathrm{O}_{4}$ : $\mathrm{Eu}^{2+}$, $\mathrm{Dy}^{3+}$ phosphors heated at various temperatures for $3 \mathrm{~h}$. The emission wavelength was fixed at $524 \mathrm{~nm}$. Inset shows the position of the excitation peaks of the phosphors prepared at various temperatures for $3 \mathrm{~h}$.

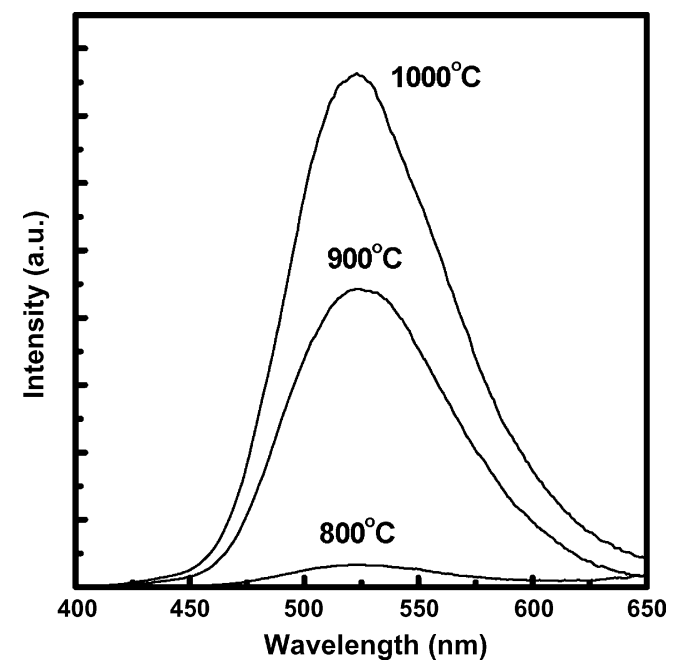

Fig. 5. Emission spectra of the reverse microemulsion derived $\mathrm{SrAl}_{2} \mathrm{O}_{4}: \mathrm{Eu}^{2+}$, $\mathrm{Dy}^{3+}$ phosphors heated at various temperatures for $3 \mathrm{~h}$. The excitation wavelength was fixed at $360 \mathrm{~nm}$.

phosphors is also shown in the inset of Fig. 4. When the calcination temperature decreased, the respective peak position shifted toward shorter wavelengths. The blue shift phenomenon was also found in other studies related to nanosized $\mathrm{SrAl}_{2} \mathrm{O}_{4}$ phosphors $[7,8,15]$. When the grain size decreases to nano-scaled, the surface energy increases significantly, resulting the change of the crystal field around the local environment of $\mathrm{Eu}^{2+}$ and the corresponding shift in the excitation spectra.

Fig. 5 depicts the emission spectra of the prepared phosphors monitored for 360-nm excitation. A broad emission peak was observed at around $524 \mathrm{~nm}$, revealing the characteristic emission of $\mathrm{Eu}^{2+}$ activators $\left(4 \mathrm{f}^{6} 5 \mathrm{~d}^{1} \rightarrow 4 \mathrm{f}^{7}{ }^{8} \mathrm{~S}_{7 / 2}\right)$ parity allowed transition) [5]. Both the excitation and emission intensities of the prepared phosphors increased with the increase in calcination temperature because of enhanced crystallinity at elevated temperatures which results in less non-radiation recombination. The decay time of microemulsion derived $\mathrm{SrAl}_{2} \mathrm{O}_{4}$ phosphors calcined at various temperatures was studied. The decay curves of the prepared phosphors were fitted using the following equation:

$I=a \exp \left(\frac{-t}{\tau_{1}}\right)+b \exp \left(\frac{-t}{\tau_{2}}\right)$

where $I$ is the phosphorescence intensity, $a$ and $b$ are the constants, $t$ is the time, and $\tau_{1}$ and $\tau_{2}$ are decay times for the exponential components $[16,17]$. The obtained fitting results were illustrated in Table 1. The obtained data are close to those reported in literature. According to the above results, it is confirmed that nanosized $\mathrm{SrAl}_{2} \mathrm{O}_{4}: \mathrm{Eu}^{2+}, \mathrm{Dy}^{3+}$ phosphors with good

Table 1

Decay time constants of $\mathrm{SrA}_{2} \mathrm{O}_{4}: \mathrm{Eu}^{2+}, \mathrm{Dy}^{3+}$ phosphors heated at various temperatures

\begin{tabular}{rlc}
\hline & $\tau_{1}(\min )$ & $\tau_{2}(\min )$ \\
\hline $900^{\circ} \mathrm{C}$ & 0.67 & 12.06 \\
$1000^{\circ} \mathrm{C}$ & 4.06 & 36.80 \\
\hline
\end{tabular}


emission properties were successfully obtained. The developed process can be applied to synthesize other kinds of phosphors.

\section{Conclusions}

$\mathrm{SrAl}_{2} \mathrm{O}_{4}: \mathrm{Eu}^{2+}, \mathrm{Dy}^{3+}$ phosphors were successfully obtained via a reverse microemulsion process at a temperature as low as $900{ }^{\circ} \mathrm{C}$. This synthesis temperature was much lower than that required in the conventional solid-state method for preparing pure phase. The average particle size of the $900^{\circ} \mathrm{C}$-heated phosphors was around $40 \mathrm{~nm}$, which is also much smaller than that of powders prepared via the solid-state process. These results can be ascribed to the formation of nano-scaled micelles that consequently leads to better precursor reactivity and restricted particle growth. The intensity of the excitation and emission peaks of nanosized $\mathrm{SrAl}_{2} \mathrm{O}_{4}: \mathrm{Eu}^{2+}, \mathrm{Dy}^{3+}$ phosphors significantly increased with the increase in heating temperatures.

\section{References}

[1] K. Yokota, S.X. Zhang, K. Kimura, J. Lumin. 92 (2001) 223.
[2] D. Ravichandran, R. Roy, W.B. White, S. Erdei, J. Mater. Res. 12 (1997) 819.

[3] A. Ellens, F. Zwaschka, F. Kummer, A. Meijerink, M. Raukas, K. Mishra, J. Lumin. 93 (2001) 147.

[4] G. Blasse, A. Bril, Philips Res. Rep. (1968) 201.

[5] H. Lange, U.S. Patent, No. 3,294,699 (1966).

[6] N.A. Sirazhiddinov, P.A. Arifov, Zhurnal Neorganicheskoi Khimii 16 (1971) 76.

[7] Z. Tang, F. Zhang, Z. Zhang, C. Huang, Y. Lin, J. Eur. Ceram. Soc. 20 (2000) 2129.

[8] T. Peng, L. Huajun, H. Yang, C. Yan, Mater. Chem. Phys. 85 (2004) 68.

[9] C.H. Lu, H.C. Wang, J. Mater. Chem. 13 (2003) 428.

[10] V. Raghuveer, P.J. Ferreira, A. Manthiram, Electrochem. Commun. 8 (2006) 807.

[11] C.H. Lu, H.C. Huang, Chem. Lett. 33 (2004) 1568.

[12] C.H. Lu, H.C. Wang, J. Electrochem. Soc. 152 (2005) C341.

[13] X-ray Powder Data File, International Centre of Diffraction Data, Card No.74-0794 (1997).

[14] M. Arturo, L. Quintela, J. Colloid Interface Sci. 8 (2003) 137.

[15] D. Ravichandran, S.T. Johnson, S. Erdei, R. Roy, W.B. White, Displays 19 (1999) 197.

[16] A. Nag, T.R.N. Kutty, J. Alloys Compd. 354 (2003) 221.

[17] C. Ghang, D. Mao, J. Shen, C. Feng, J Alloys Compd. 348 (2003) 224. 